\title{
Cultural Influences on Collaborative Work in Software Engineering Teams
}

\author{
Fariba Fazli \\ University of Hamburg, Germany \\ fazli@informatik.uni-hamburg.de
}

\author{
Eva Bittner \\ University of Hamburg, Germany \\ bittner@informatik.uni-hamburg.de
}

\begin{abstract}
International business activities increasingly lead to the formation of multicultural teams that work together as project teams, for a certain time both at a site as well as in virtual teams. Despite the modern conception of many companies that multicultural composite teams are more productive due to various perspectives and work styles, the ignorance and disrespect of these differences in work styles and perspectives can lead to misunderstanding and loss of productivity. In this paper, we report our findings from a systematic literature review that analyzes previous research on cross-cultural software engineering, to identify potential impacts of national cultural factors on collaborative approaches and behavior in software engineering teams. We discuss the current emerging state of knowledge and point out directions for advancing the understanding of cultural influences in this domain to lay the foundation for better collaboration design for cross-cultural software engineering teams.
\end{abstract}

\section{Introduction}

As it has already been noted in various studies, a major reason why many process-related projects failed and still fail is the insensitivity concerning cultural values guiding the attitude and behavior of the employees involved [1]-[2]. Humphrey defines a software process as ,the set of tools, methods and practices we use to produce a software product" [3]. It has been widely recognized that cultural differences have implications for design and usability, while the cultural impacts on the collaborative interaction within the software engineering process itself still lacks a common understanding [4]. It is important to note that the concept of culture always refers to a specific group [5]. Depending on the context, this group can be a nation, an organization or a work group. Group cultures can be inhomogeneous in the sense that subgroups within a certain group can exist, which form overlapping cultural identities [6]- [7]. For this reason, culture is a very complex concept that often consists of various intertwined group cultures Since software development is a human-centered process, the human factors have different levels of impact in the software engineering (SE) process varying from organizational and interpersonal to individual. The human factors in SE processes can be studied from different perspectives such as sociological, management and technical aspects. Our study focuses on culture as a human factor in SE and particularly the individual national culture.

Dedicated research and analysis of various special features of workgroups would be needed to illuminate the extent, to which the various cultural factors influence SE. In order to address this need and shed light on these relationships, we have reviewed relevant literature on cross-cultural SE to identify and characterize cultural factors influencing the SE process from development lifecycle and software management perspectives.

The idea behind this systematic review is to investigate and review studies related to $\mathrm{SE}$ management as well as individual and interpersonal culture factors. The main focus of the paper is to analyze national culture factors from two main perspectives, on the one hand the SE management perspective and on the other hand the collaboration perspective in SE teams. The paper is organized as follows: Section two gives a brief background on the concept of culture and the dimensions of cultural variation used in the analysis. Section three describes the research methodology, research questions and project process steps in detail. Section four includes the analysis and results of the systematic review. Section five identifies, analyzes and discusses validity threats of the review. Finally, the conclusion and future work has been brought in section six.

\section{Theoretical background}

\subsection{Software engineering and software engineering processes}

SE is defined as "the application of engineering to the design, development, implementation and 
maintenance of software in a systematic method" [8]. "Software engineering refers to the disciplined application of engineering, scientific, and mathematical principles and methods to the economical production of quality software" [9].

"The software engineering process is the total set of software engineering activities needed to transform a user's requirements into software. This process may include, as appropriate, requirements specification, design, implementation, verification, installation, operational support, and documentation. It also may include either temporary or long term repair and/or enhancement to meet continuing needs. The term maintenance is not used here since its meaning is not universally accepted" [9].

A software process is "a set of work activities, actions, and tasks that are required to build software. The aim of a software process is to produce high quality software within budget, and time. The process can be seen as a road map, which guides project participants about the necessities to successfully complete the project" [10].

Jaakkola et al. notice the increasing distribution and geographical dislocation of SE work, which underlines the importance of work management and organization. [11] If the effects of cultural differences on distributed agile teams are not known and understood well, they can result in severe problems in distributed projects. Therefore, ways to bridge the cultural differences in these teams need to be explored. [12] To address this need, the main focus of this study is to analyze national culture factors from two perspectives in the SE process: the SE management perspective and the collaboration perspective in SE teams.

\subsection{Culture}

Different definitions of culture exist in different research fields [13], [14], [15], [16], [17]. Most of these definitions have a common aspect: culture is learned, culture is associated with values and beliefs and behaviors that are shared by a group, and these values are passed along from generation to generation [6], [14], [15].

Other researchers have attempted to define the various dimensions that underpin culture through empirical research. Hall (1989), defines cultures on the basis of a way of communicating along a dimension from 'high-context' to 'low-context'. For Hall, culture is communication, which consists of verbal expression (words), power and status expression (material things), and feeling expression (behavior) [16].

Hofstede (2005) explains culture as "collective programming of the mind which distinguishes the members of one group from another" and consists of "common characteristics", that influence a group's response to its environment" [6]. "Culture refers to the shared values of a group that become visible in actions and structures" [14]. The authors of the GLOBE study interpret culture as "shared motives, values, beliefs, identities, and interpretations or meanings of significant events that result from common experiences of members of collectives that are transmitted across generations" [15].

\subsection{Cultural dimensions}

In the following section we introduce cultural factors underlying our analysis. Various prominent culture researchers pursuited to find observable indicators for cross-cultural comparisons and identified different cultural dimensions.

Kluckhohn and Strodtbeck (1961) studied culture from the perspective of value orientations. They identified five areas in which all cultural groups have fundamental, though differing, beliefs. These value orientations represent how a culture views human nature, the relationship of its people with nature, time, or collective focus, and whether space is public or private. For each of the orientations, Kluckhohn and Strodtbeck identify 3 relative positions where a culture may stand.

- Human Nature: People are born good, evil, or a mixture of both.

- Person vs. Nature: People value their subjugation to nature, mastery over nature, or harmony with nature.

- Time Sense: Priority is given to traditional customs, future plans, or present events.

- Social Relations: Society is organized around a lineal hierarchy of authority, collateral interests, or individual goals.

- Space: Business and life is conducted publicly or privately, or a mix of the two. [17]

Hall (1989) identifies key cultural dimensions based on time and communication patterns. He classifies cultures as high-context cultures, in which importance is given to the context rather than the content, and low-context cultures, in which importance is given to the content. Based on time, he classifies cultures as monochronic cultures that perceive time linearly performing one activity at a time and polychronic cultures that perceive time more flexibly by allowing activities to be performed simultaneously [16].

Hofstede (2011) is one of the most widely cited cultural researchers. Based on a large scale study of IBM employees located in over 40 countries Hofstede developed the following cultural dimensions: 1) 
individualism/collectivism; 2) power distance; 3) uncertainty avoidance; 4) masculinity/femininity; 5) long term orientation.

Individualism/Collectivism describes, how an individual is perceived in a culture: according to individual characteristics or by the characteristics of the group to which (s)he belongs to. A highly individualistic culture is one where individual interests take precedence over collective ones and everyone is expected to look after himself/herself.

Power Distance measures the extent to which a culture embraces social inequality. High power distance cultures are characterized by a strong sense of hierarchy, a preference for differentiated status and restricted communication between members belonging to different levels of the hierarchy. A culture with low power distance, on the other hand, considers every individual as equal, despite difference in power, status or wealth.

Uncertainty Avoidance is the level of risk accepted by a culture. The uncertainty avoidance index indicates the tolerance a culture exhibits towards unfamiliar or ambiguous situations.

Masculinity/Femininity reflects that either masculine norms such as success and material orientation or feminine norms like relationship, people orientation and quality of life are important in a culture. A more masculine culture has more distinct social gender roles Gender roles in a feminine culture are more fluid.

Long-Term/Short-Term Orientation is the level to which a society takes a long-term versus a short term orientation in life; a culture with long-term orientation prescribes to long- term commitments and perseverance towards slow results [13].

These identified dimensions have been used in many research fields to identify the cultural influence on Information Systems initiatives. However, Hofstede's dimensions have often been criticized. Myers et al. notice that the nation-state is a relatively new phenomenon that did not exist for the major part of human history. [18] In line with that argumentation, McSweeney questions nations as the proper units of analysis as cultures are not necessarily reflected by borders. [19] In spite of this criticism, Hofstede's dimensions have been widely used to analyze crosscultural communication between organizations or to explore the potential influence of culture in the process of software development.

As discussed above, various definitions of culture exist in different research fields. Many researchers define culture dimensions based on various assumptions. Culture is a very complex concept and difficult to grasp, especially in the highly interactive and multifaceted field of SE. It is essential to study the previous findings on how cultural differences manifest in SE and how they may impact collaboration in crosscultural SE teams in this literature review. These findings could help to gain a clearer understanding of the relationship between the SE initiatives and human interaction to optimize future SE approaches.

\section{Literature review}

Global business activities increasingly lead to forming multicultural teams. The ignorance and disrespect of the differences in work styles and perspectives can result in misunderstanding and lost productivity. In this systematic literature review, we analyze previous research on cross-cultural $\mathrm{SE}$, to identify potential impacts of national cultural factors on collaborative approaches and behavior in SE teams.

The literature review methodology includes three main phases, planning, conducting and documenting using Kitchenham's "Guidelines for performing Systematic Literature Reviews in Software Engineering" [20]. The research questions, data sources, iteration steps, and extraction, are discussed in the following subsections.

\subsection{Research questions}

The following research questions were designed to investigate the studies in the area of cultural influence factors for teamwork in SE initiatives.

1. Do previous studies indicate influences of national culture on SE team? How do these influences manifest?

2. How does national cultural background of team members affect the collaborative work in SE teams?

3. Which SE activities are influenced by the cultural background of the team members?

4. What are the open research questions for further research in this field?

These questions are answered in section four.

\subsection{Focused searches}

To find studies in SE research related to cultural influences, a set of different combinations of selected keywords was generated and searched through four well-known databases for the domain under study:

- ACM Digital library (portal.acm.org/dl.cfm)

- IEEE Xplore (www.ieexplore.ieee.org) 
- Web of Science

(www.thomsonreuters.com/WebOfScience)

- Elsevier Science Direct

\begin{tabular}{|c|c|c|c|c|c|}
\hline & S1 & S2 & S3 & S4 & S5 \\
\hline $\begin{array}{c}\text { ACM } \\
\text { Digital } \\
\text { Library }\end{array}$ & 374 & 195 & 76 & 39 & 14 \\
\hline $\begin{array}{c}\text { IEEE } \\
\text { Xplore }\end{array}$ & 677 & 344 & 28 & 12 & 3 \\
\hline $\begin{array}{c}\text { Web of } \\
\text { Science }\end{array}$ & 34 & 15 & 1 & 1 & 0 \\
\hline $\begin{array}{c}\text { Science } \\
\text { direct }\end{array}$ & 45 & 11 & 1 & 1 & 1 \\
\hline $\begin{array}{c}\text { Backward } \\
\text { search }\end{array}$ & - & - & - & 5 & 2 \\
\hline Total & $\mathbf{1 1 3 0}$ & $\mathbf{5 6 5}$ & $\mathbf{1 0 7}$ & $\mathbf{5 6}$ & $\mathbf{2 0}$ \\
\hline
\end{tabular}

(www.sciencedirect.com)

\section{Table 1: Number of papers included after each selection phase}

S1: Initial search

S2: Paper focus on culture

S3: Paper focus on national culture

S4: Paper focus on software production

S5: Collaboration in SE teams

In a first step the words culture, software engineering and software development have been searched for in various combinations, in the mentioned digital databases within the titles, abstracts and keywords (depending on the database options), from the publication year of 2000 onwards (S1). We filtered the papers with deeper focus on culture, by reading the abstracts and conclusion of all papers and choosing those papers for further analysis, which used culture as a central concept in their studies (S2). In a second iteration we sorted out all the papers without focus on national culture by reading the whole paper (S3). The research questions in this systematic review are related to SE teams involved in software development processes or SE, not on cultural influences on software usage. In a third step we thus excluded the software user centered studies to reflect the development focus (S4). We refined our searching with one more question, "if and how does culture affect the collaborative work in SE teams?" (S5). Finally, we inspected the references of the initially found papers and the references made to those papers in a backward and forward search and included five additional papers, meeting the selection criteria (see Table 1).

\section{Results}

\subsection{Identified cultural differences}

There are many studies using Hofstede's cultural dimension. As shown below, in some cases these studies found evidence for Hofstede's scores and in others not. Lee et al. (2011) identified significant inconsistencies between measured Hofstede scores for developers taking part in their survey and predicted scores, which they take as indication for questionability of Hofstede`s applicability in relation to IT development. [21]

Other studies leaving the culture dimension path, identified cultural differences in e. g. work styles. In Dorairaj et al.'s study on "Bridging cultural differences" e.g. one participant noted: "The biggest challenge usually is to understand the work culture. The American way of doing things is so different from [the] European. In my personal experience, working in India and China is not so different...the work culture is exactly the same" [12].

Furthermore, Verner et al. summarize "The Australian developers had quite different attitudes from the US developers even though culturally Australia and the US are considered fairly similar. The Chilean software engineers' motivation levels show some similarities to the US software engineers" [22].

Table 2 summarizes the findings of empirical studies about cultural differences in SE, compared by culture dimensions $(\mathrm{CD})$. 


\section{Table 2. Cultural differences compared by culture dimensions (CD)}

\begin{tabular}{|c|c|}
\hline CD & \\
\hline $\begin{array}{l}\text { Hofstede`s } \\
\text { CD }\end{array}$ & $\begin{array}{l}\text { "We found a very good correspondence of expected and actual values for uncertainty avoidance, } \\
\text { and a good result for power distance and masculinity. Less good results are found for individuality, } \\
\text { which shows an inverted order of values" [23]. } \\
\text { "while the analysis of variance found differences among the four cultures on team performance ..., it } \\
\text { found no significant differences among the four cultural groups on any of the cultural dimensions" } \\
\text { [24]. } \\
\text { "The relative view of the Anglo West and China developers, is that defects are not solely due to } \\
\text { inadequate testing, suggesting the quality assurance view. In contrast the Indian developers seem } \\
\text { to take the quality control approach" [21]. } \\
\text { "It is not clear why collectivism and long term orientation would map to productivity and the reverse } \\
\text { to quality. However, it is worth noting that in associated work we identified significant inconsistencies } \\
\text { between scores for developers who took part in our survey and predicted Hofstede scores, shedding } \\
\text { further questionability over Hofstede in relation to IT development" [21]. } \\
\text { "Chinese are collectivism valued: } \\
\text { - the risk of deviation from schedule is weaken. } \\
\text { - it is a little easier to have a good relation with customer" [25]. }\end{array}$ \\
\hline $\begin{array}{l}\text { Hofstede`s } \\
\text { power } \\
\text { distance }\end{array}$ & $\begin{array}{l}\text { "High power distance countries team members feel comfortable with authoritative relationships } \\
\text { where they are told what to do. } \\
\text { Low power distance countries subordinates prefer managers who are consultative. Individuals } \\
\text { feel self-motivated and more productive when there is less intervention by the managers"[26]. } \\
\text { "Chinese are high power distance valued: while people obey their boss' order, the boss is easy to } \\
\text { neglect employees' desire, which will make employees be low morale and discouraged"[25]. } \\
\text { "High power distance. Assignees from cultures with greater respect for expected managers to make } \\
\text { decisions and provide guidance and supervision" [27]. } \\
\text { "The low power distance customer managers: tended to have more egalitarian expectations for their } \\
\text { employees to take initiative, participate, and give honest feedback even if it was critical"[27]. }\end{array}$ \\
\hline $\begin{array}{l}\text { Halls } \\
\text { CD }\end{array}$ & $\begin{array}{l}\text { "The results suggest that cultural communication styles (low- context vs. high context) might be } \\
\text { more prominent in intra- cultural settings than inter-cultural settings"[28]. } \\
\text { "the American participants from a low-context communication style culture were more likely to } \\
\text { explicitly discuss information sharing and organization strategies than the Chinese participants"[28]. } \\
\text { "at the dyadic level of analysis, American participants in the American-American intra-cultural } \\
\text { computer supported collaboration condition were more likely to discuss strategies for information } \\
\text { sharing and information organization than participants in the Chinese-Chinese intra- cultural } \\
\text { condition" [28]. } \\
\text { "the significant differences are between the two intra-cultural groups and not with the inter-cultural } \\
\text { group"[28]. }\end{array}$ \\
\hline
\end{tabular}

\subsection{Identified influence fields}

Some studies in the sample find that cultural differences may influence e.g. collaborative work factors [28], [24] and SE techniques [29]. There are many SE activities identified that are impacted by cultural aspects. For example, in one study, the
American participants from a low-context communication style culture discussed rather more about information sharing and organization strategies than the participants from the Chinese high-context communication style culture. [28] The prevalent indication for cultural influences during collaborative work in global SE shall lead us to design further 
studies in order to find new ways for effective realization of the team staffing and management using these differences. The following Table 3 shows cultural influences on SE initiatives observed in different studies. The first column comprises of two categories, namely the SE management aspect and the team member behavior aspect. The second column represents the observed influences presented in the research papers.

Table 3. Observed influences on ...

\begin{tabular}{|c|c|}
\hline Field & Observed influences on \\
\hline $\begin{array}{l}\mathrm{SE} \\
\text { management } \\
\text { aspects }\end{array}$ & $\begin{array}{l}\text { success of the project [21], [22] } \\
\text { business goals [30] } \\
\text { team performance [24] } \\
\text { quality and productivity [21], [24] } \\
\text { the expectations on SE team } \\
\text { member [27] } \\
\text { expectations of management [27] } \\
\text { control mechanisms in SE [26] } \\
\text { risk assessment, risk mitigation and } \\
\text { planning [25] } \\
\text { software modeling activities [31] } \\
\text { software testing activities [32] } \\
\text { information sharing and organization } \\
\text { in computer supported collaboration } \\
\text { [28] } \\
\text { collaborative work factors [28], [24] } \\
\text { software engineering techniques [29] }\end{array}$ \\
\hline $\begin{array}{l}\mathrm{SE} \text { team } \\
\text { member } \\
\text { behavior }\end{array}$ & $\begin{array}{l}\text { information sharing [28] } \\
\text { work organization [28], [24] } \\
\text { team motivation [22] } \\
\text { the expectations on management[27] }\end{array}$ \\
\hline
\end{tabular}

\begin{tabular}{|l|l|}
\hline & $\begin{array}{l}\text { communication styles [34], [12] } \\
\text { work behaviors, act [34], [12] }\end{array}$ \\
\hline
\end{tabular}

\subsection{Identified research needs}

As Matthiesen et al. notice "Working in a global setting changes the conditions for IT development, and we need to figure out how we can support the expert IT developers, who have the critical business knowledge to better work in global setups" [35]. In line with this request, we aim to identify questions that should be addressed in future research to reach this goal and lead to better guidance and support of global SE teams. From the conducted literature review, we could derive a research agenda covering three main areas. Table 4 presents the identified research questions for further research about cultural aspects influencing the SE collaboration. In the first section the needs in the global software engineering (GSE) area are shown and in the following sections identified research needs concerning SE management activities and team collaboration are presented. This analysis points out to the great variety of yet unanswered questions in this emergent field of rising importance for both research and practice.

\section{Table 4. Identified research gaps}




\begin{tabular}{|c|c|}
\hline Area & Research needs \\
\hline GSE & $\begin{array}{l}\text { "Cultural differences have the potential to have even more significant differences within the global } \\
\text { software development model. The implications are of interest not just to us as human factor } \\
\text { specialists but also to those operating more strategically, both clients and project managers"[36]. } \\
\text { "Working in a global setting changes the conditions for IT development, and we need to figure out } \\
\text { how we can support the expert IT developers, who have the critical business knowledge to better } \\
\text { work in global setups[35]. } \\
\text { "Future research should explore in more detail how cultural tensions work to enable global } \\
\text { collaboration" [27]. } \\
\text { "Lack of knowledge on the effect of cultural differences on distributed Agile teams can lead to } \\
\text { major problems in distributed projects. The Agile practitioners need to explore ways to bridge the } \\
\text { cultural differences in the team"[12]. }\end{array}$ \\
\hline $\begin{array}{l}\text { SE } \\
\text { manageme } \\
\text { nt activities }\end{array}$ & $\begin{array}{l}\text { "Cultural differences, especially cultural conflicts should be recognized, which will be helpful in risk } \\
\text { identification, risk assessment. Other analysis can also be made based on action feature impacted } \\
\text { by culture" [25]. } \\
\text { "Creating a fit between culture differences and control mechanisms will help managers in } \\
\text { successfully managing OOISD projects"[26]. }\end{array}$ \\
\hline $\begin{array}{l}\text { Teamwork } \\
\text { /team } \\
\text { collaborati } \\
\text { on }\end{array}$ & $\begin{array}{l}\text { "Further research is also required into the effects that culture has on team motivation"[22]. } \\
\text { "Given the divergent empirical findings on cultural influences in socio-technical settings, lacking a } \\
\text { coherent body of findings, due caution must be exercised in drawing inferences that go beyond } \\
\text { the cultural background of the participants, the collaborative task, and the technological } \\
\text { environment" [28]. } \\
\text { "To sum up, the culture and attitudes about groups appear to have had the most affect on a } \\
\text { group's ability, followed by individual characteristics. Recent research completed by the GLOBE } \\
\text { project may be used to inform this project about possible cultural clusters that distinguish among } \\
\text { the different countries". Performance[24]". } \\
\text { "Only a real experiment of cross cultural collaborative ontology design might provide data for } \\
\text { evaluating all the hypotheses including those concerning the structure of conceptualization and } \\
\text { the type of design contribution. This could be an objective of future research work" [23]. }\end{array}$ \\
\hline
\end{tabular}

\section{Discussion}

Our analysis and findings indicate that for instance cultural differences influence the success of the project [21], [22] and business goals [37]. There are many SE activities identified that are impacted by cultural aspects.

Most researchers notice the limitation of validation of their empirical data. The difficulty to present valid and reliable argumentation from empirical studies is

characteristic for the research in cultural context using cultural dimensions. As Lee et al. (2011) explain

"It is not clear why collectivism and long term orientation would map to productivity and the reverse to quality.

However, it is worth noting that in associated work we identified significant inconsistencies between scores for developers who took part in our survey and predicted Hofstede's scores, shedding further questionability over Hofstede in relation to IT development." However, they suggest that "(...) the presence of cultural differences may give rise to different notions of truth, potentially affecting the success of the offshoring project. We have seen here that cultural differences have the potential to have even more significant differences within the global software development model and that the implications are of interest not just to us as human factor specialists but also to those operating more strategically, both clients and project managers" [36]. 
In recent research, alternative approaches arise to explore the questions in this field, e.g. a combination of cultural dimension and other environmental influences. Ayouby et al. (2012) see the need to explore other, more dynamic approaches than the national culture approach to study culture in information system research. They argue that culture is not pure, but fluid and constantly evolving over time. [38]

In the dynamic model of culture, culture is seen as being capable of changing in response to external forces [39]. Leung et al. understand culture to be represented by cognitive structures and cognitive processes that are sensitive to environmental influences. [39]

Other scholars notice that, while the use of culture dimensions can help to gain a different perspective on specific situations, it also bears the risk of overgeneralization of conclusions by stereotyping. [40] This argument against using such dimensional approaches should be considered. Thus, viewing culture purely in the form of dimensions may miss the important characteristics of culture as being dynamic and gradually transforming in nature [40]. One emergent idea in this stream of research is the idea of thinking in terms of cultural models, as "patterns that govern conventional behaviors". [41] Shah et al. mention not being predetermined as the key advantage of cultural models is. In their perspective, humans, as cognitive and sociocultural beings, constantly create and enact cultural models. The researchers argue that determining these enacted models through detailed in ethnographic and narrative studies, will help to better understand how and why culture affects the GSE practice [40].

\section{Conclusion}

National culture differences have been shown to have a significant impact on team interaction in some settings [27]. Authors in the field agree on the perspective that culture plays an important role for the success of SE projects. Most of the studies on culture and SE use a culture dimensions' approach (e.g., Hofstede's or Hall's approach to define culture). However, others discuss the limitations of this view[38]- [40]- [18].

In this paper, we make three main contributions. First, we describe the concepts of cultural dimensions that are predominantly used in the SE discipline. We identify the studies in SE research with a focus on individual culture. Second, we illustrate the interesting findings of the selected papers exploring cultural aspects and their impacts on collaborative work. Third, we discuss the limitations of culture as dimension perspective presenting other extended perspectives/models to enhance future studies in the field.

Our general findings indicate that there are differences e.g. in communication styles, interaction in teams, decision-making and more during collaboration as it has been explored in various studies. Discovered geographical, temporal and cultural differences have substantial influences on the interaction of team members in distributed teams, especially on communication, coordination and control aspects. [42]

As Dorairaj et al. (2011) stress, significant problems may arise in distributed projects through the ignorance of cultural differences in distributed agile teams. [12] We found strong support in the reviewed publications for conducting in-depth-studies on culture and collaboration in GSE teams in order to better understand and manage their dynamics.

\subsection{Future research}

Narayanaswamy et al. (2005) notice "with globalization becoming a prominent trend in IT industry, it is increasingly important to understand how to tackle cross-cultural issues. Doing so will not only help lead to more effective project management practices but also to a world of increased cross-cultural understanding" [26].

Narayanaswamy et al. (2005) notice that understanding cross-cultural issues gains importance in times of the rising and prominent trend of globalization in IT. Such understanding would enable more effective project management as well as more cross-cultural understanding. [26]

Thus, follow up research should aim to gain deeper insights on the initial exploratory findings from the studies presented in this paper. In particular, the suggested correlations of cultural aspects and different collaborative behaviors should be investigated further. Further research should also dive into the effects of culture on team motivation. [22] Furthermore, the suitability of different management styles and SE practices for different cultural indications are a promising field for future studies.

As this literature review shows, research on cultural impacts on collaborative and cross-cultural SE is still in its early stages. Due to the growing importance of GSE and account the fact, that the volume of GSE Projects has significantly increased during the period considered, more research needs to identify and alleviate the specific challenges faced by multicultural distributed teams in this area. 
There are still many open questions to be answered. Based on the research needs from the reviewed publications, these might be for instance the question:

- What aspects of collaboration are affected more by culture than others?

- What are alternative or complementary ways to conceptualize culture in SE to the culture-asdimension perspective?

- How does national culture influence the information sharing and communication and organization during collaboration in SE teams?

- What differences exist in productivity and quality understanding due to team members' cultural differences?

The review at hand is a first step to shed light on these issues and to better understand the interrelation of culture and SE success. Pursuing this aim, research in this field should work towards being able to design and manage better collaborative SE practices for crosscultural teams.

\section{References}

[1] G. Cao, S. Clarke, and B. Lehaney, “A critique of BPR from a holistic perspective," Business Process Mgmt Journal, vol. 7, no. 4, pp. 332-339, 2001.

[2] R. G. Lee and B. G. Dale, "Business process management: A review and evaluation," Business Process Mgmt Journal, vol. 4, no. 3, pp. 214-225, 1998.

[3] W. S. Humphrey, Managing the software process, 28th ed. Boston: Addison-Wesley, 2002.

[4] A. Marcus and E. W. Gould, "Crosscurrents: Cultural dimensions and global Web user-interface design," interactions, vol. 7, no. 4, pp. 32-46, 2000.

[5] D. E. Leidner and T. Kayworth, "Review: a review of culture in information systems research: toward a theory of information technology culture conflict," MIS Quarterly, vol. 30, no. 2, pp. 357-399, 2006.

[6] G. H. Hofstede and G. J. Hofstede, "Cultures and organizations: Software ofthe mind. Revised and expanded, 2,” d Ed. New York: McGraw-Hill, 2005.

[7] S. P. Huntington, The clash of civilizations and the remaking of world order: Penguin Books India, 1997.

[8] A. Abran, Ed, Guide to the software engineering body of knowledge, 2004 version: SWEBOK ; a project of the IEEE Computer Society Professional Practices Committee. Los Alamitos, Calif.: IEEE Computer Society, 2004.
[9] W. S. Humphrey, "The Software Engineering Process: Definition and Scope," SIGSOFT Softw. Eng. Notes, vol. 14, no. 4, pp. 82-83, http://doi.acm.org/10.1145/75111.75122, 1988.

[10] R. S. Pressman, Software engineering: a practitioner's approach: Palgrave Macmillan, 2005.

[11] H. Jaakkola, J. Henno, B. Thalheim, and J. Makela, "Collaboration, distribution and culture - challenges for communication," in 2015 38th International Convention on Information and Communication Technology, Electronics and Microelectronics (MIPRO), pp. 657-664.

[12] S. Dorairaj, J. Noble, and P. Malik, "Bridging Cultural Differences: A Grounded Theory Perspective," in Proceedings of the 4th India Software Engineering Conference, New York, NY, USA: ACM, 2011, pp. 3-10.

[13] G. Hofstede, Culture's consequences: Comparing values, behaviors, institutions, and organizations across nations, 2nd ed. Thousand Oaks, Calif.: Sage Publ, 20[11.

[14] E. H. Schein, Organizational culture and leadership: John Wiley \& Sons, 2006.

[15] R. J. House, P. J. Hanges, M. Javidan, P. W. Dorfman, and V. Gupta, Culture, leadership, and organizations: The GLOBE study of 62 societies: Sage publications, 2004.

[16] E. T. Hall, Beyond culture. New York, NY: Anchor Books, 1989.

[17] F. R. Kluckhohn and F. L. Strodtbeck, "Variations in value orientations," 1961.

[18] M. Myers, "D. and Tan, F, B. Beyond models of national culture in information systems research," Advanced Topics in Global Information Management, pp. 14-29, 2002.

[19] B. McSweeney and Essex Univ, Colchester . Dept. of Accounting, Finance and Management, Knowing what is to be established: the fallacy of national culture identification: Department of Accounting, Finance and Management, University of Essex, 2000.

[20] P. Brereton, B. A. Kitchenham, D. Budgen, M. Turner, and M. Khalil, "Lessons from applying the systematic literature review process within the software engineering domain," Journal of systems and software, vol.

[21] D. Lee, A. Smith, and M. Mortimer, "Cultural Differences Affecting Quality and Productivity in Western/Asian Offshore Software Development," in Proceedings of the 3rd International Conference on Human Computer Interaction, New York, NY, USA: ACM, 2011, pp. 29-39.

[22] J. Verner, S. Beecham, and N. Cerpa, "Stakeholder 
Dissonance: Disagreements on Project Outcome and Its Impact on Team Motivation Across Three Countries," in Proceedings of the 2010 Special Interest Group on Management Information System's 48th Annual Conference on Computer Personnel Research on Computer Personnel Research, New York, NY, USA: ACM, 2010, pp. 25-33.

[23] L. Anticoli and E. Toppano, "The Role of Culture in Collaborative Ontology Design," in Proceedings of the 2011 International Conference on Intelligent Semantic WebServices and Applications, New York, NY, USA: ACM, 2011, p. 4:1.

[24] K. Swigger et al, "Structural Factors That Affect Global Software Development Learning Team Performance," in Proceedings of the Special Interest Group on Management Information System's 47th Annual Conference on Computer Personnel Research, New York, NY, USA: ACM, 2009, pp. 187-196.

[25] Wenting Ma, Lin Liu, Wenzhong Feng, Yuhui Shan, and Fei Peng, "Analyzing Project Risks Within a Cultural and Organizational Setting," in Proceedings of the 2009 ICSE Workshop on Leadership and Management in Software Architecture, Washington, DC, USA: IEEE Computer Society, 2009, pp. 6-14.

[26] R. Narayanaswamy and R. M. Henry, "Effects of Culture on Control Mechanisms in Offshore Outsourced IT Projects," in Proceedings of the 2005 ACM SIGMIS CPR Conference on Computer Personnel Research, New York, NY, USA: ACM, 2005, pp. 139-145.

[27] J. L. Gibbs, "Culture As Kaleidoscope: Navigating Cultural Tensions in Global Collaboration," in Proceedings of the 2009 International Workshop on Intercultural Collaboration, New York, NY, USA: ACM, 2009, pp. 89-98.

[28] R. K. Vatrapu and D. D. Suthers, "Cultural Influences in Collaborative Information Sharing and Organization," in Proceedings of the 3rd International Conference on Intercultural Collaboration, New York, NY, USA: ACM, 2010, pp. 161-170.

[29] G. Borchers, "The software engineering impacts of cultural factors on multi-cultural software development teams," in 25th International Conference on Software Engineering, 2003. Proceedings, pp. 540-545.

[30] B. Wong and S. Hasan, "Cultural influences and differences in software process improvement programs," in the 6 th international workshop, pp. 3-10.

[31] A. B. Cunha, A. G. Canen, and M. A. M. Capretz, "Personalities, cultures and software modeling: Questions, scenarios and research directions," in 2009 ICSE Workshop on Cooperative and Human Aspects on Software Engineering, pp. 23-31.

[32] H. Shah and M. J. Harrold, "Culture and Testing: What is the Relationship?," in 2013 IEEE 8th International Conference on Global Software Engineering (ICGSE), pp. $51-60$.

[33] E. MacGregor, Y. Hsieh, and P. Kruchten, "Cultural patterns in software process mishaps," in the 2005 workshop, pp. 1-5.

[34] H. Huang and E. M. Trauth, "Cultural influences and globally distributed information systems development," in the 2007 ACM SIGMIS CPR conference, p. 36.

[35] S. Matthiesen, P. Bjørn, and L. M. Petersen, "Figure out How to Code with the Hands of Others": Recognizing Cultural Blind Spots in Global Software Development," in Proceedings of the 17th ACM Conference on Computer Supported Cooperative Work \& Social Computing, New York, NY, USA: ACM, 2014, pp. 1107-1119.

[36] David Lee, Andy Smith, Mike Mortimer, "Cultural differences affecting quality and productivity in Western / Asian offshore software development," 2011.

[37] B. Wong, Proceedings of the 6th international workshop on Software quality. New York, NY: ACM, 2008.

[38] R. Ayouby, A.-M. Croteau, and L. Raymond, "Acculturation to the Global Culture and Internet Adoption," SIGMIS Database, vol. 43, no. 4, pp. 33-54, http://doi.acm.org/10.1145/2398834.2398838, 2012.

[39] K. Leung, R. S. Bhagat, N. R. Buchan, M. Erez, and C. B. Gibson, "Culture and international business: Recent advances and their implications for future research," Journal of International Business Studies, pp. 357-378, 2005.

[40] H. Shah, N. J. Nersessian, M. J. Harrold, and W. Newstetter, "Studying the Influence of Culture in Global Software Engineering: Thinking in Terms of Cultural Models," in Proceedings of the 4th International Conference on Intercultural Collaboration, New York, NY, USA: ACM, 2012, pp. 77-86.

[41] B. Shore and J. Bruner, Culture in mind: Cognition, culture, and the problem of meaning, 1st ed. New York, NY: Oxford Univ. Press, 1998.

[42] P. J. Agerfalk et al, "A framework for considering opportunities and threats in distributed software development," 2005. 